\title{
Prognostic value of XIAP and survivin expression in locally advanced breast cancer patients treated with anthracycline-based neoadjuvant chemotherapy
}

Piotr Pluta ${ }^{1}$, Dorota Jesionek-Kupnicka², Agnieszka Pluta ${ }^{3}$, Kamil Brzozowski³ ${ }^{3}$ Marcin Braun², Joanna Kubicka-Wołkowska ${ }^{4}$, Janusz Piekarski ${ }^{5}$

\begin{abstract}
${ }^{1} 1^{\text {st }}$ Department of Surgical Oncology, Copernicus Memorial Hospital, Lodz, Poland 2Department of Cancer Pathology, Medical University of Lodz, Lodz, Poland ${ }^{3}$ Department of Hematology, Medical University of Lodz, Copernicus Memorial Hospital, Lodz, Poland

${ }^{4}$ General Oncology Counseling Center, Copernicus Memorial Hospital, Lodz, Poland ${ }^{5}$ Department of Surgical Oncology, Medical University of Lodz, Copernicus Memorial Hospital, Lodz, Poland
\end{abstract}

Submitted: 19 May 2019; Accepted: 19 August 2019

Online publication: 7 October 2019

Arch Med Sci 2023; 19 (2): 343-354

DOI: https://doi.org/10.5114/aoms.2019.88509

Copyright @ 2019 Termedia \& Banach

\begin{abstract}
Introduction: Neoadjuvant treatment in locally advanced breast cancer (LABC) is intended to decrease the cancer mass, increase the likelihood of radical resection and improve survival. Resistance to chemotherapy may depend on cellular expression of anti-apoptotic proteins. XIAP and survivin are the most potent inhibitors of apoptosis (IAP), but their role in drug-induced cancer cell apoptosis remains unclear. This study was designed to evaluate the impact of pre-treatment expression of XIAP and survivin on pathological complete response and survival in $L A B C$ patients.

Material and methods: The study included 60 LABC patients treated with anthracycline-based chemotherapy. XIAP and survivin expression was assessed immunohistochemically in pre-treatment core biopsy specimens.

Results: Pathological complete response was achieved in 33\% of the LABC patients. Low/intermediate expression of both XIAP and survivin was significantly associated with pathological complete response $(p \leq 0.04$ and $p<0.001$, respectively) and positively correlated with disease-free survival $(p=0.017$ and $p<0.001)$ and overall survival $(p=0.052$ and $p<0.001)$. The area under receiver operating characteristics curves (AUC) revealed predictive value of survivin expression for relapse and death in breast cancer patients ( $A \cup C=0.63, p=0.001$ and $A U C=0.8, p<0.001$, respectively).

Conclusions: Our findings suggest that downregulation of XIAP and survivin in $L A B C$ patients might predict better treatment outcomes after anthracycline-based chemotherapy. This, in turn, may indicate XIAP and survivin proteins as potential targets for innovative anticancer therapies.
\end{abstract}

Key words: apoptosis, prognosis, breast neoplasm.

\section{Introduction}

Despite broad access to screening programmes, there has been little reduction in the number of advanced stage breast cancers at diagnosis [1-3]. Locally advanced breast cancer (LABC) is a non-metastatic and potentially curable disease, which presents a wide variety of clinical charac-
Corresponding author: Piotr Pluta MD, PhD $1^{\text {st }}$ Department of Surgical Oncology Copernicus Memorial Hospital in Lodz 62 Pabianicka St 93-513 Lodz, Poland Phone: +48604188 815 E-mail: drpiotrpluta@gmail.com 
teristics such as large invasive tumour, extension to the skin or chest wall, massive nodal involvement or inflammatory breast cancer [4]. In such patients, the neoadjuvant treatment is intended to decrease the cancer mass and increase the likelihood of radical resection. Additionally, the therapy response positively correlates with the survival $[5,6]$. Despite introduction of novel hormonal agents and chemotherapeutic regimens, LABC patients' treatment still remains challenging due to the high risk of disease recurrence [7, 8]. One prospective way to improve the long-time outcome in the disease is through a molecular tailored strategy based on exploration of cancer cell biology.

Apoptosis is a process by which aberrant, damaged or unwanted cells are eliminated from a multicellular body [9]. In the case of cancer cells, resistance to apoptosis is one of the principle mechanisms of their immortalization. The Inhibitors of Apoptosis Proteins (IAP) play a key role in this process and their upregulation is likely to be inherent to cancer cell development $[10,11]$. The IAP family is a class of anti-apoptotic proteins defined by the presence of one or three Baculovirus IAP repeat (BIR) domains, which are hence also termed BIR-containing proteins (BIRCs). These domains are responsible for inhibiting apoptosis by binding the active sites of caspases, which are the crucial proteases in apoptotic pathways. However, inhibiting caspases is not the sole function of IAPs; they also contribute to cell cycle control, ubiquitination of proteins and receptor-mediated signalling [12]. Eight mammalian IAP proteins have been described including cellular IAP1 (cIAP1), cellular IAP2 (cIAP2), X chromosome-linked IAP (XIAP), survivin, BIR repeat-containing ubiquitin-conjugating enzyme system (BRUCE), neuronal apoptosis inhibitory protein (NAIP), melanoma IAP (MLIAP) and IAP-like protein 2 (ILP2) [10].

$\mathrm{XIAP}$ is considered the most potent caspasebinding protein and is known to inhibit both the intrinsic (mitochondrial directed) and extrinsic (death receptor directed) apoptosis pathways [13]. It contains three BIR domains and is the only IAP family member to inhibit caspases through a direct physical interaction [14]. High expression of XIAP has been found to be associated with resistance to chemotherapy in various malignancies and a few studies have presented its clinical role in breast cancer patients [13, 15-21].

Survivin contains a single BIR domain and with its molecular weight of $16.389 \mathrm{kDa}$ it is the smallest member of the IAP family [22]. It is typically present during fetal development but is almost absent in normal adult tissues [23]. Survivin expression is markedly increased in most malignancies; however, its impact on chemoresistance and a poor prognosis in breast cancer patients is still uncertain [2428]. The oncogenic role of survivin depends mainly on its role in inhibiting both the intrinsic and extrinsic apoptosis pathways and enabling aberrant proliferation by mitotic control [10, 23].

A previous flow cytometry analysis in early breast cancer demonstrated XIAP and survivin to have higher median expression in more advanced tumours, and hence to possess the most significant prognostic importance among IAP family members [19]. Following these findings, the present study seeks to verify the role of XIAP and survivin in $\angle A B C$ and to assess their impact on the pathological response after chemotherapy and on long-term survival. To assess protein expression the present study uses immunohistochemistry rather than flow cytometry, as it is, in our opinion, a more affordable and practical technique.

\section{Material and methods}

\section{Patient inclusion}

The Research Ethics Committee of the Medical University of Lodz has approved the project protocol. The study group involved female patients with locally advanced breast cancer (LABC) who received neoadjuvant chemotherapy followed by surgery and adjuvant treatment between January 2006 to December 2011 in the Department of Chemotherapy and the Department of Surgical Oncology, Copernicus Memorial Hospital, Lodz, Poland. Inclusion criteria encompassed LABC patients with complete clinical data and available tissue samples. We excluded LABC male patients and those who received preoperative endocrine therapy. The pathological assessment of XIAP and survivin protein expression was conducted in pre-chemotherapy tumours. All the patients gave their written informed consent.

The retrospective clinical data of consecutive patients were retrieved from the medical record system. Of the $98 \mathrm{LABC}$ patients whose data were available in our database, 60 of them met the eligibility criteria and were included in the study group. The median age of those patients was 53.5 years (range: $29-74$ years).

The initial clinical stage of the disease was classified according to the $7^{\text {th }}$ edition of the Union for International Cancer Control TNM Classification of Malignant Tumours [29]. The study group patients received the neoadjuvant chemotherapy with four to six cycles, performed every 3 weeks and consisting of doxorubicin $\left(60 \mathrm{mg} / \mathrm{m}^{2}\right)$ and cyclophosphamide $\left(600 \mathrm{mg} / \mathrm{m}^{2}\right)$, or doxorubicin $\left(50 \mathrm{mg} / \mathrm{m}^{2}\right)$ and docetaxel $\left(75 \mathrm{mg} / \mathrm{m}^{2}\right)$. Subsequently, all the patients underwent a modified mastectomy with axillary lymph node dissection and were irradiated postoperatively. Adjuvant hormone therapy and trastuzumab were administered depending on the receptor expression. 


\section{Pathological assessment} and immunohistochemistry

The diagnosis of invasive breast carcinoma was performed according to the standard pathological protocol, which encompassed tumour type and grading, the status of the oestrogen receptor (ER), progesterone receptor (PR) and human epidermal growth factor receptor type 2 (HER-2). ER and PR receptor statuses were assessed using immunohistochemistry (IHC) and scored according to the Allred system [30]. Immunohistochemical expression of HER-2 receptor was evaluated using the standard protocol ( 0 and $1+-$ negative, $2+-$ equivocal, $3+-$ positive). For IHC equivocal HER-2 (2+) status, fluorescent in situ hybridization (FISH) was performed so as to examine gene amplification.

The pathological complete response $(p C R)$ to chemotherapy in the postoperative specimens was defined as the absence of invasive cancer in postoperative breast specimens, irrespective of ductal carcinoma in situ and axillary lymph node status (ypT0/is). A non-pathological complete response (non-pCR) was established in cases which did not fulfil the above criterion.

In order to examine the pre-treatment expression of XIAP and survivin, formalin-fixed, paraffin-embedded blocks (FFPE) of core biopsy were examined immunohistochemically as previously described [31]. Monoclonal IgG1 anti-hXIAP antibody, clone 117318 (RD Systems, Minneapolis, MN, USA) in dilution 1 : 40, pH 6.0 and IgG antihSurvivin antibody, clone AF886 (RD Systems, Minneapolis, MN, USA) in dilution 1 : 100, pH 6.0 were used for XIAP and survivin examination, respectively. Prostate specimens were used as positive controls according to the recommendation of the antibody manufacturer.

Two pathologists scored the results independently according to Perrone et al., with modifications [32]. The extent of expression was scored based on the percentage of immunopositivity cells as follows: 0 for < 1\%; 1 for $1-20 \%$; 2 for $21-50 \%$; 3 for $51-80 \%$; 4 for $>80 \%$. The intensity of staining was classified as 0 for weak, 1 for moderate and 2 for strong. The immunopositivity and intensity scores were summed up to give a final score, interpreted as low expression for a score of 0 , intermediate expression for 2-4 and high expression for 5-6. XIAP and survivin expression was assessed in the whole cells, collectively for cytosol and nuclear staining.

\section{Statistical analysis}

The dichotomic variables were compared using the $\chi^{2}$ test with the corresponding corrections to the numbers of cases in the subgroups. The Tau-b Kendall rank correlation coefficient
( $R$ tau-b) was calculated using the $\chi^{2}$ test. The coefficient of correlation was assessed on the basis of ranges established by Cohen: a correlation coefficient greater than 0.6 indicated a strong correlation, 0.3-0.6 indicated a moderate correlation, and less than 0.3 indicated a poor correlation [33]. Disease-free survival (DFS) was calculated from the date of diagnosis until the documentation of relapse. Overall survival (OS) was calculated from the date of diagnosis until death or the date of the last contact with the patients. DFS and OS were assessed applying the Kaplan-Meier method. The logrank test was used to compare OS and DFS in the subgroups. The impact of clinicopathological factors on OS and DFS was calculated using the Cox proportional-hazards model univariate and multivariate analyses. Median follow-up was calculated using reverse Kaplan-Meier curves [34]. To calculate the best cut-off we used receiver operating characteristics (ROC) curves and Youden's index. The area under ROC curves (AUC) was calculated to assess the predictive value of the tested factors [35]. P-values less than 0.05 were considered statistically significant. Statistica 13 software (Dell inc, Tulsa, OK, USA) was used for statistical calculation.

\section{Results}

XIAP and survivin expression in the pre-treatment biopsies

In the core biopsy, XIAP expression was assessed as low, intermediate and high in 17 (28\%), 29 (48\%) and 14 (23\%) cases, respectively. Similarly, survivin expression was scored as low in 16 (27\%) cases, intermediate in 24 (40\%) cases and high in 20 (33\%) cases. Figure 1 depicts examples of XIAP and survivin expression related to the scoring subdivision. In the dichotomic analysis, low/intermediate expression of XIAP and survivin comprised 46 (76\%) cases and 40 (67\%) cases, respectively vs. high expression of XIAP (14 cases; $23 \%$ ) and survivin (20 cases; $33 \%$ ). A positive correlation was observed between XIAP and survivin expression $(p<0.001$; R tau-b $=0.42)$.

\section{Relationship between XIAP and survivin expression and clinical/pathological parameters}

Regarding the relationship between IAP protein expression and clinical and pathological parameters, expression of XIAP moderately correlated with disease stage, as lower XIAP expression prevailed in the more advanced disease (96\% low/ intermediate vs. $71 \%$ high XIAP expression in stage III; $p=0.033)$. Neither XIAP nor survivin expression was correlated with other clinical and pathological factors. The detailed results are presented in Tables I and II. 

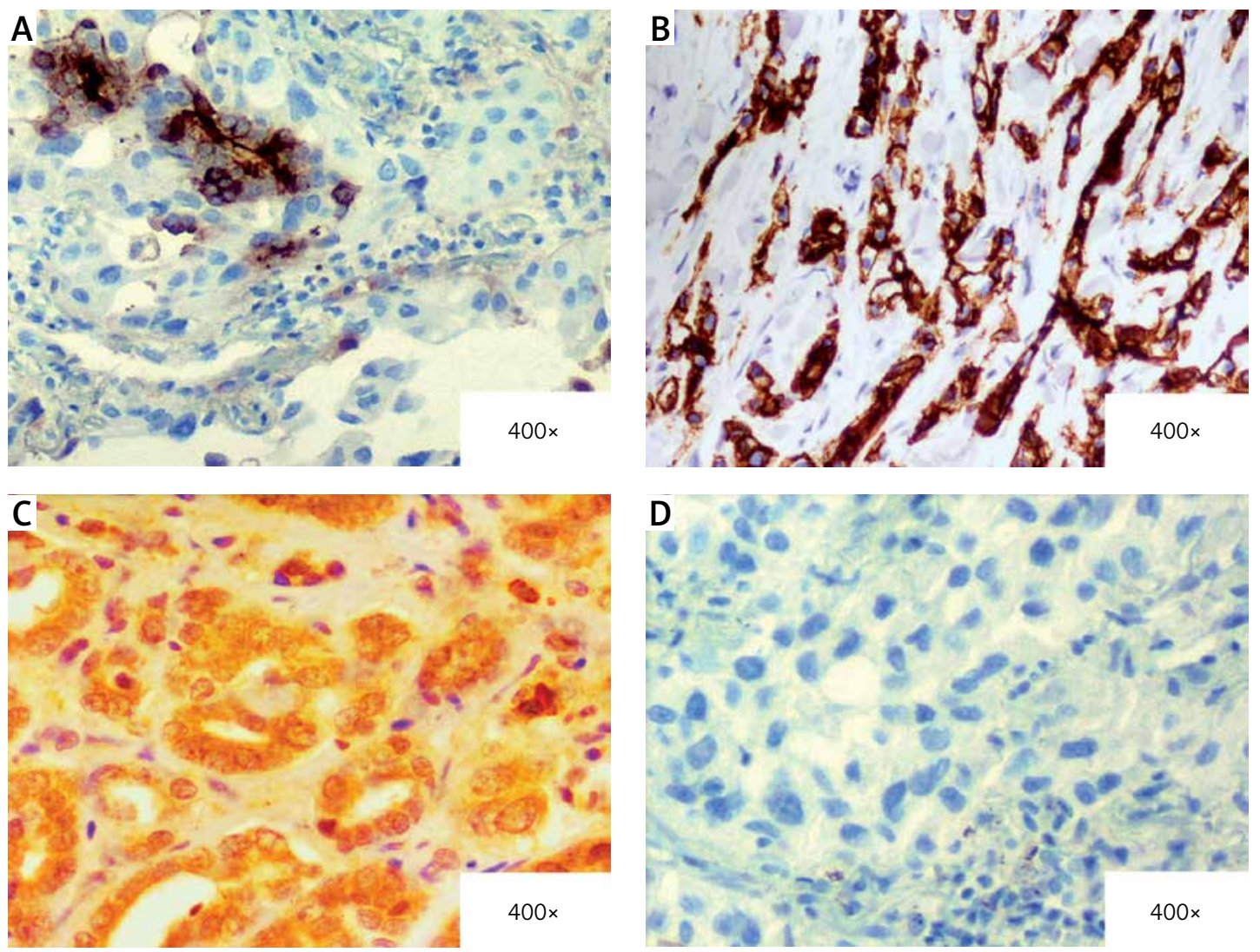

Figure 1. Examples of immunohistochemical staining of XIAP and survivin in pretreatment specimens of locally advanced breast cancer (LABC). A - Intermediate expression of XIAP (25\% of cells positive (2 points); intensity: strong (2 point); total score): 4. B - High expression of XIAP ( $90 \%$ of cells positive (4 points); intensity: strong (2 points); total score: 6). C - High expression of survivin in cytosol and nuclei (100\% of cells positive (4 points); intensity: strong (2 points); total score: 6$)$. $\mathbf{D}$ - Case negative for expression ( $0 \%$ of cells positive)

\section{XIAP and survivin expression and pathological response to chemotherapy}

Pathological complete response was achieved by 20 out of the 60 study participants (33\%). Low/ intermediate XIAP expression was significantly associated with $\mathrm{pCR}$ ( $41 \%$ low/intermediate vs. $7 \%$ high XIAP expression in the $\mathrm{PCR}$ subgroup; $p=0.04)$. Similarly, low/intermediate expression of survivin in tumour correlated with post-chemotherapy achievement of pCR (50\% low/intermediate vs. $0 \%$ high survivin expression in the $\mathrm{pCR}$ subgroup; $p<0.001)$. Among the clinical and pathological parameters, HER-2 positive receptor status inversely correlated with pCR $(15 \%$ pCR in the HER-2 positive patients vs. $47 \% \mathrm{pCR}$ in the HER-2 negative patients; $p=0.021$ ). The association between clinicopathological variables and pCR rates is shown in Table III.

\section{XIAP and survivin expression and survival}

At a median follow-up of 96.5 months, 19 patients developed locoregional recurrence or distant metastases. Fifteen patients died during the follow-up.
The Kaplan-Meier analyses revealed that lower XIAP and survivin expression was associated with longer disease-free survival (DFS) $(p=0.017$ and $p<0.001$, respectively, Table IV, Figures 2 A, B). Better DFS was also observed in the patients with lack of a HER2 receptor and PCR achievement ( $p=$ 0.019 and $p=0.001$, respectively).

Longer overall survival (OS) was observed in the patients with low/intermediate survivin expression in comparison to high expression ( $p<$ 0.001 , Table IV, Figure 2 C). The patients with $p C R$ had longer OS as compared to the non-PCR group $(p=0.001$, Table IV).

In the multivariate Cox analysis survivin ex- pression was confirmed as the only independent risk factor for a longer DFS and OS (in both cases $p<0.001$, Table V). Additionally, the area under ROC curves (AUC) analysis revealed a predictive value of survivin expression for relapse and death in breast cancer patients (AUC $=0.63, p=0.001$ and $\mathrm{AUC}=0.8, p<0.001$ respectively; Table VI). Survivin had low sensitivity to non-PCR anticipation. Prediction of non-PCR, relapse and death was not confirmed in relation to XIAP expression. 
Table I. Relationship between XIAP expression and clinicopathological factors of the 60 locally advanced breast cancer patients

\begin{tabular}{|c|c|c|c|c|c|c|}
\hline \multirow[t]{2}{*}{ Parameter } & & \multicolumn{2}{|c|}{ XIAP expression } & \multirow[t]{2}{*}{$P$-value } & \multirow{2}{*}{$\begin{array}{l}\text { Contingency } \\
\text { coefficient }\end{array}$} & \multirow{2}{*}{$\begin{array}{c}\text { Tau b } \\
\text { Kendall }\end{array}$} \\
\hline & & $\begin{array}{c}\text { Low/intermediate } \\
n(\%)\end{array}$ & $\begin{array}{l}\text { High } \\
n(\%)\end{array}$ & & & \\
\hline Patients, $n$ & 60 & $46(77)$ & $14(23)$ & & & \\
\hline \multirow[t]{2}{*}{ Age [years] } & $<50$ & $16(27)$ & $5(8)$ & 0.949 & 0.008 & -0.01 \\
\hline & $\geq 50$ & $30(50)$ & $9(15)$ & & & \\
\hline \multirow[t]{2}{*}{ Tumour size } & $\mathrm{T} 1 / \mathrm{T} 2$ & $23(38)$ & $7(12)$ & 1.000 & 0.00 & 0.00 \\
\hline & $\mathrm{T} 3 / \mathrm{T} 4$ & $23(38)$ & $7(12)$ & & & \\
\hline \multirow[t]{2}{*}{ TNM stage } & IIB & $2(3)$ & $4(7)$ & 0.033 & 0.32 & -0.34 \\
\hline & III & $44(73)$ & $10(17)$ & & & \\
\hline \multirow{2}{*}{$\begin{array}{l}\text { Histological } \\
\text { type }\end{array}$} & NST & $43(72)$ & 11(18) & 0.104 & 0.21 & 0.21 \\
\hline & $\mathrm{LOB}$ & $3(5)$ & $3(5)$ & & & \\
\hline \multirow{2}{*}{$\begin{array}{l}\text { Histological } \\
\text { grade }\end{array}$} & $\mathrm{G} 2$ & $22(37)$ & $8(13)$ & 0.542 & 0.08 & -0.08 \\
\hline & $\mathrm{G3}$ & $24(40)$ & $6(10)$ & & & \\
\hline \multirow[t]{2}{*}{ ER status } & Negative & $26(43)$ & $6(10)$ & 0.370 & 0.12 & 0.12 \\
\hline & Positive & $20(33)$ & $8(13)$ & & & \\
\hline \multirow[t]{2}{*}{ PR status } & Negative & $25(42)$ & $5(8)$ & 0.222 & 0.16 & 0.16 \\
\hline & Positive & $21(35)$ & $9(15)$ & & & \\
\hline \multirow[t]{2}{*}{ HER-2 status } & Negative & $28(47)$ & $6(10)$ & 0.234 & 0.15 & 0.15 \\
\hline & Positive & $18(30)$ & $8(13)$ & & & \\
\hline \multirow[t]{2}{*}{ Triple negative } & No & $30(50)$ & $11(18)$ & 0.347 & 0.12 & -0.12 \\
\hline & Yes & $16(27)$ & $3(5)$ & & & \\
\hline
\end{tabular}

$N S T$ - invasive carcinoma of no special type, LOB - invasive lobular carcinoma, ER - oestrogen receptor, PR - progesterone receptor, HER2 - human epidermal growth factor receptor type 2.

\section{Discussion}

Overexpression of IAP family members has been repeatedly encountered in various cancers cells, yet their prognostic and predictive roles in various clinical scenarios remain uncertain [13]. The present report assesses expression of XIAP and survivin, two highly potent IAP proteins, in $\mathrm{LABC}$ patients undergoing an anthracycline-based chemotherapy with regard to $\mathrm{PCR}$ and survival.

In the study, high XIAP expression was detected in $33 \%$ of patients and was inversely associated with disease stage. In contrast, Xu et al. did not observe any significant correlation between high XIAP expression and breast cancer stage, as a high cytosolic fraction of this protein was detected in $18 \%$ of patients in stage II and in $12 \%$ of patients in stage III [20]. In a large cohort presented by Hussain et al. XIAP protein was overexpressed in $29.5 \%$ of 1009 breast cancer patients, irrespective of the tumour stage and lymph node involvement [18].

Preclinical studies have demonstrated that XIAP down-regulation increases sensitivity to a cytotoxic therapy in inflammatory breast cancer cell lines, thus confirming the protective role of XIAP in drug-induced cancer cell apoptosis [36, 37]. Our results further support this hypothesis, as low/intermediate expression of XIAP was found to correlate with a higher rate of a pathological complete response to chemotherapy. To our knowledge, our report is the first to demonstrate that XIAP expression influences the pathological response to neoadjuvant chemotherapy. Nevertheless, Parton et al. failed to confirm that the pre-treatment expression of XIAP correlated with a clinical response in a previous study of 35 LABC patients [21]. On the contrary, in advanced head and neck squamous cell carcinoma, overexpression of XIAP was significantly associated with clinical resistance to the neoadjuvant cisplatin chemotherapy [17].

The survival analysis revealed a negative impact of high XIAP expression for DFS and OS in $L A B C$ patients. This is in concordance with a study conducted in a large group of breast cancer pa- 
Table II. Relationship between survivin expression and clinicopathological factors of the 60 locally advanced breast cancer patients

\begin{tabular}{|c|c|c|c|c|c|c|}
\hline \multirow[t]{2}{*}{ Parameter } & & \multicolumn{2}{|c|}{ Survivin expression } & \multirow[t]{2}{*}{$P$-value } & \multirow{2}{*}{$\begin{array}{c}\text { Contingency } \\
\text { coefficient }\end{array}$} & \multirow{2}{*}{$\begin{array}{l}\text { Tau b } \\
\text { Kendal }\end{array}$} \\
\hline & & $\begin{array}{c}\text { Low/intermediate } \\
n(\%)\end{array}$ & $\begin{array}{l}\text { High } \\
n(\%)\end{array}$ & & & \\
\hline Patients, $n$ & 60 & $40(67)$ & $20(33)$ & & & \\
\hline \multirow[t]{2}{*}{ Age [years] } & $<50$ & $15(25)$ & $6(10)$ & 0.774 & 0.07 & -0.07 \\
\hline & $\geq 50$ & $25(42)$ & $14(23)$ & & & \\
\hline \multirow[t]{2}{*}{ Tumour size } & $\mathrm{T} 1 / \mathrm{T} 2$ & $21(35)$ & $9(15)$ & 0.584 & 0.07 & -0.07 \\
\hline & $\mathrm{T} 3 / \mathrm{T} 4$ & $19(32)$ & $11(18)$ & & & \\
\hline \multirow[t]{2}{*}{ TNM stage } & II B & $3(5)$ & $3(5)$ & 0.361 & 0.12 & 0.12 \\
\hline & III & $37(62)$ & $17(28)$ & & & \\
\hline \multirow{2}{*}{$\begin{array}{l}\text { Histological } \\
\text { type }\end{array}$} & NST & $36(60)$ & $18(30)$ & 1.000 & 0.00 & 0.00 \\
\hline & LOB & $4(7)$ & $2(3)$ & & & \\
\hline \multirow{2}{*}{$\begin{array}{l}\text { Histological } \\
\text { grade }\end{array}$} & $\mathrm{G} 2$ & $18(30)$ & $12(20)$ & 0.273 & 0.14 & 0.14 \\
\hline & G3 & $22(37)$ & $8(13)$ & & & \\
\hline \multirow[t]{2}{*}{ ER status } & Negative & $22(37)$ & $8(13)$ & 0.273 & 0.14 & -0.14 \\
\hline & Positive & $18(30)$ & $12(20)$ & & & \\
\hline \multirow[t]{2}{*}{ PR status } & Negative & $23(38)$ & $9(15)$ & 0.360 & 0.12 & -0.12 \\
\hline & Positive & $17(28)$ & $11(18)$ & & & \\
\hline \multirow[t]{2}{*}{ HER-2 status } & Negative & $25(42)$ & $9(15)$ & 0.197 & 0.16 & -0.17 \\
\hline & Positive & $15(25)$ & $11(18)$ & & & \\
\hline \multirow[t]{2}{*}{ Triple negative } & No & $25(42)$ & $16(27)$ & 0.170 & 0.17 & 0.18 \\
\hline & Yes & $15(25)$ & $4(7)$ & & & \\
\hline
\end{tabular}

$N S T$ - invasive carcinoma of no special type, $L O B$ - invasive lobular carcinoma, ER - oestrogen receptor, PR - progesterone receptor, HER-2 - human epidermal growth factor receptor type 2.

tients $(n>1000)$, which showed that overexpression of XIAP is an independent poor prognostic factor for survival [18]. In contrast, Xu et al. noted a lack of correlation between XIAP expression and survival, except for a subgroup of triple negative breast cancer, in which the presence of high XIAP levels in the tumour was associated with an increased risk of a relapse [20].

Unlike XIAP, the clinical role of survivin was thoroughly explored in breast cancer patients including those with LABC. Survivin overexpression has been found both in breast cancer cell lines and in tumour tissues [21,38]. In our study expression of survivin was correlated with XIAP expression, which suggests a similar contribution of this protein to breast cancer development. We did not find any relationship between survivin expression and clinicopathological factors of LABC patients, but in a meta-analysis conducted by Li et al., high survivin expression was observed significantly more frequently in stage III/IV of the disease [25]. In the present study, survivin overexpression was detected in $23 \%$ of the pre-treatment biopsies; these findings are similar to those of Zhao et al., who noted high staining of survivin in $33 \%$ of stage III breast cancer patients [39].

Our findings also indicate a correlation between survivin and $p C R$, since low/intermediate expression of this protein had a significant impact on pCR achievement. Zhao et al. also found that lack of survivin expression in IHC assessment was significantly associated with pCR [39]. However, another study found high survivin expression to be associated with a good response to chemotherapy $[40,41]$. Lin et al. observed that in LABC patients the response rate to anthracycline/taxanes preoperative chemotherapy was higher in survivin positive breast tumours [40]. Sensitivity to preoperative chemotherapy in $L A B C$ patients may depend not only on the main "wild-type" survivin variant, but also on different transcript forms such as survivin-3B, survivin- $\Delta \mathrm{Ex} 3$ and survivin-2B [42]. Moreover, Faversani et al. demonstrated that overexpression of survivin- $\Delta \mathrm{Ex} 3$ preserves breast 
Table III. Clinicopathological parameters and expression of XIAP and survivin in relation to pathological complete response $(p C R)$

\begin{tabular}{|c|c|c|c|c|c|c|}
\hline Parameter & & $\begin{array}{c}\text { non-pCR } \\
n(\%)\end{array}$ & $\begin{array}{c}\mathrm{pCR} \\
n(\%)\end{array}$ & $P$-value & $\begin{array}{l}\text { Contingency } \\
\text { coefficient }\end{array}$ & Tau b Kendall \\
\hline \multirow[t]{2}{*}{ Age [years] } & $<50$ & $13(22)$ & $8(13)$ & 0.775 & 0.074 & -0.074 \\
\hline & $\geq 50$ & $27(45)$ & $12(20)$ & & & \\
\hline \multirow[t]{2}{*}{ Tumour size } & $\mathrm{T} 1 / \mathrm{T} 2$ & $19(32)$ & $11(18)$ & 0.587 & 0.07 & -0.07 \\
\hline & $\mathrm{T} 3 / \mathrm{T} 4$ & $21(35)$ & $9(15)$ & & & \\
\hline \multirow[t]{2}{*}{ TNM stage } & IIB & $4(7)$ & $2(3)$ & 0.648 & 0.00 & 0.00 \\
\hline & III & $36(60)$ & $18(30)$ & & & \\
\hline \multirow{2}{*}{$\begin{array}{l}\text { Histological } \\
\text { type }\end{array}$} & NST & $36(60)$ & $18(30)$ & 0.648 & 0.00 & 0.00 \\
\hline & LOB & $4(7)$ & $2(3)$ & & & \\
\hline \multirow{2}{*}{$\begin{array}{l}\text { Histological } \\
\text { grade }\end{array}$} & G2 & $20(33)$ & $10(17)$ & 1.000 & 0.00 & 0.00 \\
\hline & G3 & $20(33)$ & $10(17)$ & & & \\
\hline \multirow[t]{2}{*}{ ER status } & Negative & $19(32)$ & $11(18)$ & 0.587 & 0.07 & -0.07 \\
\hline & Positive & $21(35)$ & $9(15)$ & & & \\
\hline \multirow[t]{2}{*}{ PR status } & Negative & $21(35)$ & $11(18)$ & 0.856 & 0.02 & -0.02 \\
\hline & Positive & $19(32)$ & $9(15)$ & & & \\
\hline \multirow[t]{2}{*}{ HER-2 status } & Negative & $18(30)$ & $16(27)$ & 0.021 & 0.32 & -0.33 \\
\hline & Positive & $22(37)$ & $4(7)$ & & & \\
\hline \multirow[t]{2}{*}{ Triple negative } & No & $29(48)$ & $12(20)$ & 0.331 & 0.13 & 0.13 \\
\hline & Yes & $11(18)$ & $8(13)$ & & & \\
\hline \multirow[t]{2}{*}{$\begin{array}{l}\text { XIAP } \\
\text { expression }\end{array}$} & $\begin{array}{l}\text { Low/ } \\
\text { intermediate }\end{array}$ & $27(45)$ & $19(32)$ & 0.040 & 0.29 & -0.31 \\
\hline & High & $13(22)$ & $1(2)$ & & & \\
\hline \multirow[t]{2}{*}{$\begin{array}{l}\text { Survivin } \\
\text { expression }\end{array}$} & $\begin{array}{l}\text { Low/ } \\
\text { intermediate }\end{array}$ & $20(33)$ & $20(33)$ & $<0.001$ & 0.45 & 0.50 \\
\hline & High & $20(33)$ & 0 & & & \\
\hline
\end{tabular}

NST - invasive carcinoma of no special type, $L O B$ - invasive lobular carcinoma, ER - oestrogen receptor, PR - progesterone receptor, $H E R-2$ - human epidermal growth factor receptor type 2, $p C R$ - pathological complete response, non-pCR - non-pathological complete response.

cancer cells from the first-line anthracycline-based chemotherapy [43]. They also found that the anti-survivin small molecule sepantronium bromide (YM155), which acts as a transcriptional suppressant of the survivin locus, incorporated into a doxorubicin regimen, induced apoptosis in tumour cells.

In the present study low pre-treatment survivin expression and survival correlated with better OS and DFS. In the multivariate analysis we also found that survivin expression is an independent risk factor for DFS and OS. We also demonstrated predictive value of survivin expression for relapse and death. These findings are similar to the study of Zhao et al., which also revealed that LABC patients with low survivin protein expression treated with anthracycline-based neoadjuvant chemotherapy had a better prognosis [39]. A gene expression study confirmed that survivin overexpression can serve as a negative prognostic factor but only in a subgroup of breast cancer patients, who did not achieve pCR after the neoadjuvant chemotherapy [44]. In contrast, Span et al. reported that patients in a post-chemotherapy subgroup with high cytosolic survivin expression achieved significantly longer progression-free survival than those with a low level [28]. Two meta-analyses of breast cancer patients found high survivin expression to be a poor prognostic factor for overall survival, irrespective of the disease stage $[25,26]$.

There are some limitations of our study. In the study, $33 \%$ of the patients achieved pCR, which is higher than in many other previous studies [45, 46]. This difference may partly result from the 
Table IV. Clinicopathological parameters and expression of XIAP and survivin in relation to disease-free survival and overall survival

\begin{tabular}{|c|c|c|c|c|c|c|c|c|}
\hline \multirow[t]{2}{*}{ Parameter } & \multicolumn{4}{|c|}{ DFS } & \multicolumn{4}{|c|}{ os } \\
\hline & $\begin{array}{c}\text { Probability } \\
\text { of 10-year } \\
\text { DFS }\end{array}$ & $\mathrm{HR}$ & $95 \% \mathrm{Cl}$ & $\begin{array}{l}\text { Log-rank } \\
p \text {-value }\end{array}$ & $\begin{array}{c}\text { Probability } \\
\text { of 10-year } \\
\text { OS }\end{array}$ & $\mathrm{HR}$ & $95 \% \mathrm{Cl}$ & $\begin{array}{c}\text { Log-rank } \\
p \text {-value }\end{array}$ \\
\hline Age [years]: & & & & 0.653 & & & & 0.157 \\
\hline$<50$ & $65.8 \%$ & 0.802 & $0.304-2.113$ & & $80.8 \%$ & 0.418 & $0.114-1.48$ & \\
\hline$\geq 50$ & $62.6 \%$ & & & & $63.6 \%$ & & & \\
\hline Tumour size: & & & & 0.608 & & & & 0.799 \\
\hline $\mathrm{T} 1 / \mathrm{T} 2$ & $62.3 \%$ & 1.271 & $0.508-3.182$ & & $66.7 \%$ & 0.877 & $0.317-2.427$ & \\
\hline $\mathrm{T} 3 / \mathrm{T} 4$ & $65.1 \%$ & & & & $70.4 \%$ & & & \\
\hline TNM stage: & & & & 0.958 & & & & 0.187 \\
\hline $\mathrm{IIB}$ & $66.7 \%$ & 1.041 & $0.239-4.53$ & & $40.0 \%$ & 2.297 & $0.645-8.182$ & \\
\hline III & $63.3 \%$ & & & & $72.3 \%$ & & & \\
\hline Histological type: & & & & 0.618 & & & & 0.117 \\
\hline NST & $67.3 \%$ & 0.747 & $0.217-2.571$ & & $65.5 \%$ & ND & ND & \\
\hline LOB & $27.8 \%$ & & & & $100 \%$ & & & \\
\hline Histological grade & & & & 0.101 & & & & 0.674 \\
\hline G2 & $53.3 \%$ & 2.193 & $0.832-5.779$ & & $68.7 \%$ & 0.805 & $0.291-2.225$ & \\
\hline G3 & $76.4 \%$ & & & & $67.5 \%$ & & & \\
\hline ER status: & & & & 0.432 & & & & 0.375 \\
\hline Negative & $69.9 \%$ & 0.696 & $0.279-1.735$ & & $74.2 \%$ & 0.63 & $0.227-1.773$ & \\
\hline Positive & $56.2 \%$ & & & & $61.7 \%$ & & & \\
\hline PR status: & & & & 0.092 & & & & 0.950 \\
\hline Negative & $75.1 \%$ & 0.46 & $0.181-1.168$ & & $67.5 \%$ & 1.033 & $0.374-2.854$ & \\
\hline Positive & $51.6 \%$ & & & & $70.3 \%$ & & & \\
\hline HER-2 status: & & & & 0.019 & & & & 0.379 \\
\hline Negative & $73.6 \%$ & 0.329 & $0.128-0.844$ & & $74.1 \%$ & 0.637 & $0.231-1.76$ & \\
\hline Positive & $51.2 \%$ & & & & $61.5 \%$ & & & \\
\hline Triple negative: & & & & 0.408 & & & & 0.601 \\
\hline No & $59.5 \%$ & 1.513 & $0.544-4.206$ & & $68.1 \%$ & 1.349 & $0.429-4.24$ & \\
\hline Yes & $70.6 \%$ & & & & $68.8 \%$ & & & \\
\hline $\mathrm{pCR}$ & $88.1 \%$ & 0.124 & $0.028-0.554$ & 0.001 & $100 \%$ & ND & ND & 0.001 \\
\hline non-pCR & $48.8 \%$ & & & & $51.2 \%$ & & & \\
\hline XIAP expression: & & & & 0.017 & & & & 0.052 \\
\hline $\begin{array}{l}\text { Low/inter- } \\
\text { mediate }\end{array}$ & $75.1 \%$ & 0.304 & $0.12-0.773$ & & $78.6 \%$ & 0.332 & $0.114-0.97$ & \\
\hline High & $0 \%$ & & & & $0 \%$ & & & \\
\hline $\begin{array}{l}\text { Survivin } \\
\text { expression: }\end{array}$ & & & & $<0.001$ & & & & $<0.001$ \\
\hline $\begin{array}{l}\text { Low/inter- } \\
\text { mediate }\end{array}$ & $82.8 \%$ & 0.095 & $0.035-0.263$ & & $87.5 \%$ & 0.087 & $0.025-0.311$ & \\
\hline High & $0 \%$ & & & & $32.9 \%$ & & & \\
\hline
\end{tabular}

DFS - disease-free survival, OS - overall survival, ND - not enough data, NST - invasive carcinoma of no special type, LOB - invasive lobular carcinoma, ER - oestrogen receptor, $P R$ - progesterone receptor, HER-2 - human epidermal growth factor receptor type 2, $p C R$ - pathological complete response, non- $p C R$ - non-pathological complete response. 
A

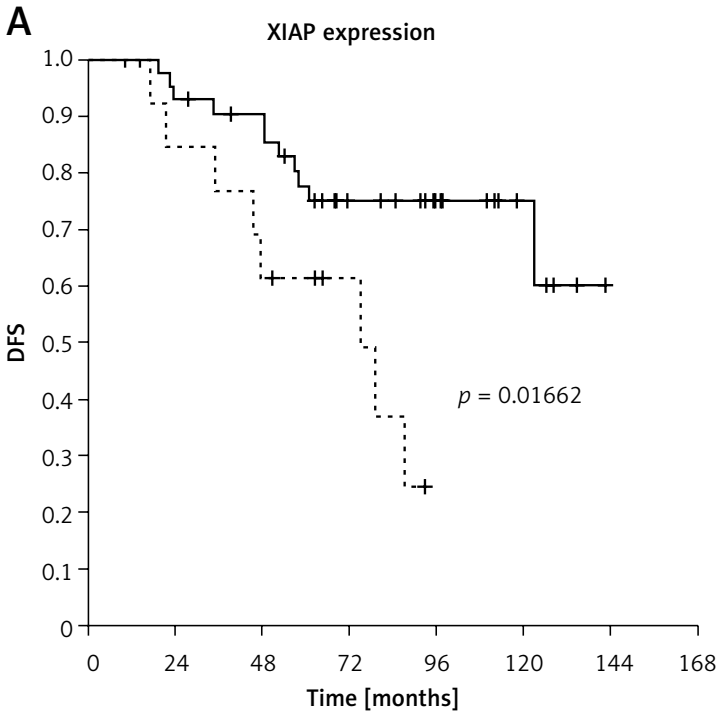

C

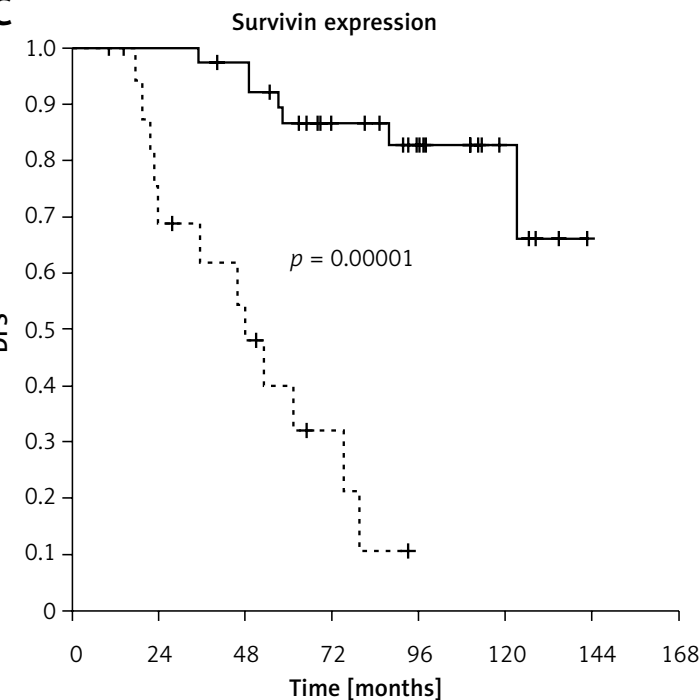

- Low and intermediate expression
B

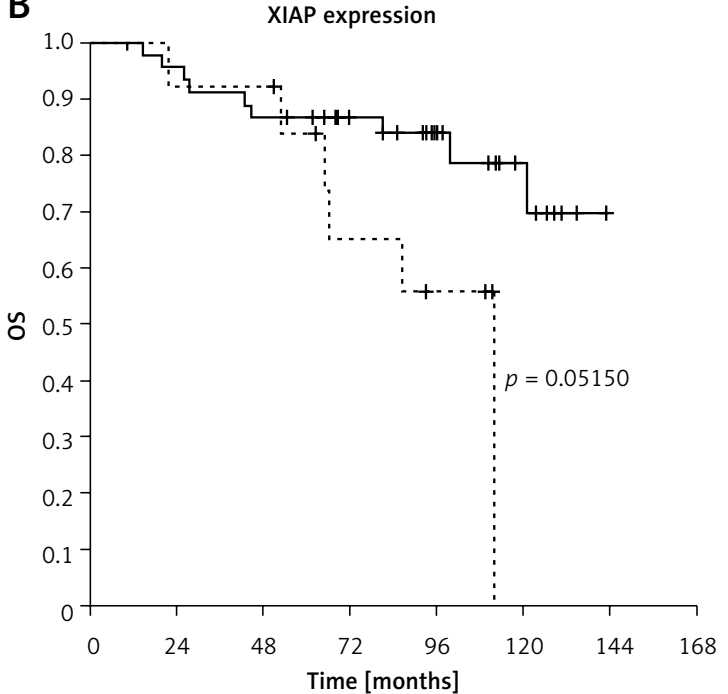

D

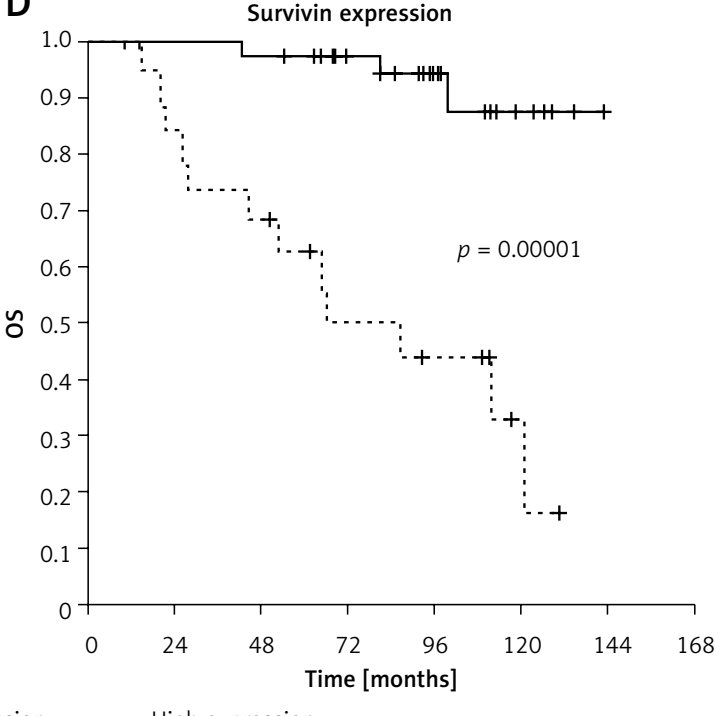

Figure 2. Kaplan-Meier curves for disease-free survival (DFS) (A, C) and overall survival (OS) (B, D) in 60 LABC patients

$\angle A B C$ - locally advanced breast cancer.

broad definition of PCR used in the study, which in this case is based on the response of the tumour invasive component: the patients with residual ductal carcinoma observed in situ (ypTo/is) in the breast tissue specimen and with any axillary lymph node status were, therefore, also included in the PCR group. However, this approach did not diminish the prognostic role of pCR in our study, since the patients who attained pCR still demonstrated better OS and DFS.

There are several well-established clinicopathological factors for pCR achievement, e.g. younger age of patients, smaller tumour size or triple negative breast cancer $[47,48]$. No such correlations were observed, which may result from the limited number of patients in our cohort or the sampling method. However, HER-2 positive receptor status was found to have a significant impact on the chance of non-pCR and DFS. This may be associated with the lack of a targeted anti-HER-2 therapy in the preoperative regimen at that time: a combined chemotherapy with trastuzumab and/or pertuzumab is currently recommended in HER-2 positive LABC patients [49].

In contrast to XIAP, which is predominantly located in the cytosol compartment, survivin is expressed in both the cytoplasm and nucleus, which implicates different molecular mechanisms of action and has a potential prognostic value $[15,19$, $25,50]$. In cancer cells, cytosol survivin has been related to inhibition of apoptosis, while nuclear survivin is more likely to be involved in aberrant proliferation. Collin et al., in a recently published case-control study encompassing a large patient 
Piotr Pluta, Dorota Jesionek-Kupnicka, Agnieszka Pluta, Kamil Brzozowski, Marcin Braun, Joanna Kubicka-Wołkowska, Janusz Piekarski

Table V. Multivariate Cox regression analysis for disease-free survival (DFS) and overall survival (OS)

\begin{tabular}{|c|c|c|c|c|c|c|}
\hline \multirow[t]{2}{*}{ Parameter } & \multicolumn{3}{|c|}{ DFS } & \multicolumn{3}{|c|}{ os } \\
\hline & HR & $95 \% \mathrm{Cl}$ & $P$-value & HR & $95 \% \mathrm{Cl}$ & $P$-value \\
\hline \multicolumn{7}{|l|}{ Age [years] } \\
\hline$<50$ vs. $\geq 50$ & 1.019 & $0.292-3.558$ & 0.976 & 0.777 & $0.181-3.331$ & 0.734 \\
\hline \multicolumn{7}{|l|}{ Tumour size: } \\
\hline T1/T2 vs. T3/T4 & 3.668 & $0.997-13.493$ & 0.06 & 1.912 & $0.586-6.238$ & 0.282 \\
\hline \multicolumn{7}{|l|}{ TNM stage: } \\
\hline IIB vs. III & 1.587 & $0.234-10.785$ & 0.636 & 1.258 & $0.222-7.139$ & 0.795 \\
\hline \multicolumn{7}{|l|}{ Histological type: } \\
\hline NST vs. LOB & 0.306 & $0.036-2.592$ & 0.277 & ND & ND & ND \\
\hline \multicolumn{7}{|l|}{ Histological grade: } \\
\hline G2 vs. G3 & 1.509 & $0.48-4.737$ & 0.48 & 0.356 & $0.109-1.165$ & 0.088 \\
\hline \multicolumn{7}{|l|}{ ER status: } \\
\hline Negative vs. positive & 5.302 & $0.692-40.598$ & 0.108 & 0.749 & $0.111-5.051$ & 0.767 \\
\hline \multicolumn{7}{|l|}{ PR status: } \\
\hline Negative vs. positive & 0.17 & $0.018-1.652$ & 0.127 & 2.304 & $0.389-13.652$ & 0.358 \\
\hline \multicolumn{7}{|l|}{ HER-2 status: } \\
\hline Negative vs. positive & 0.104 & $0.009-1.129$ & 0.063 & 0.838 & $0.162-4.333$ & 0.833 \\
\hline \multicolumn{7}{|l|}{ Triple negative: } \\
\hline No vs. yes & 0.094 & $0.006-1.556$ & 0.099 & 0.872 & $0.082-9.235$ & 0.909 \\
\hline pCR vs. non-pCR & 0.329 & $0.047-2.316$ & 0.264 & ND & ND & ND \\
\hline \multicolumn{7}{|l|}{ XIAP expression: } \\
\hline Low/intermediate vs. high & 2.58 & $0.668-9.96$ & 0.169 & 1.383 & $0.321-5.962$ & 0.663 \\
\hline \multicolumn{7}{|l|}{ Survivin expression: } \\
\hline Low/intermediate vs. high & 0.05 & $0.011-0.266$ & $<0.001$ & 0.04 & $0.007-0.218$ & $<0.001$ \\
\hline
\end{tabular}

DFS - disease-free survival, OS - overall survival, ND - not enough data, NST - invasive carcinoma of no special type, LOB - invasive lobular carcinoma, ER - oestrogen receptor, $P R$ - progesterone receptor, HER-2 - human epidermal growth factor receptor type 2, $p C R$ - pathological complete response, non-pCR - non-pathological complete response.

Table VI. Predictive value of XIAP and survivin expression for non-PCR, relapse and death

\begin{tabular}{|c|c|c|c|c|}
\hline Parameter & Sensitivity & Specificity & $\operatorname{AUC}(95 \% \mathrm{Cl})$ & AUC $p$-value \\
\hline \multicolumn{5}{|l|}{ Prediction of non-PCR: } \\
\hline XIAP low/medium vs. high (for cut-off: high) & 0.325 & 0.950 & $0.638(0.497 ; 0.778)$ & 0.056 \\
\hline Survivin low/medium vs. high (for cut-off: high) & 0.500 & 1.000 & $0.750(0,630 ; 0.870)$ & $<0.001$ \\
\hline \multicolumn{5}{|l|}{ Prediction of relapse: } \\
\hline XIAP low/medium vs. high (for cut-off: high) & 0.421 & 0.842 & $0.632(0.471 ; 0.792)$ & 0.108 \\
\hline Survivin low/medium vs. high (for cut-off: high) & $0, .632$ & 0.868 & $0.750(0.604 ; 0.896)$ & 0.001 \\
\hline \multicolumn{5}{|l|}{ Prediction of death: } \\
\hline XIAP low/medium vs. high (for cut-off: high) & 0.400 & 0.822 & $0.611(0.437 ; 0.785)$ & 0.210 \\
\hline Survivin low/medium vs. high (for cut-off: high) & 0.800 & 0.822 & $0.811(0.676 ; 0.946)$ & $<0.001$ \\
\hline
\end{tabular}

$A U C$ - area under the ROC curve, non-pCR - non-pathological complete response. 
group ( $n=541)$, did not confirm the association between cytoplasmic or nuclear survivin expression and breast cancer recurrence [51]. However, some previously conducted meta-analyses have revealed that cytoplasmic survivin overexpression is an unfavourable prognostic factor, while high expression of nuclear survivin has no impact on breast cancer prognosis $[25,26]$. Nevertheless, in the present study we assessed the expression of both proteins throughout the cell with regard to their changes in cellular distribution during the cell lifetime and their uncertain prognostic impact.

In the era of novel cancer treatment IAP family proteins have become an attractive target for anticancer therapy. BIR domains of XIAP (as well as CIAP1/2) are the aim for the small molecules also known as SMAC mimetics, which play a role similar to that of the natural IAP antagonist SMAC/ DIABLO protein (Second Mitochondria-derived ACtivator of Caspases/Direct IAp Binding with Low pl) [52]. Preclinical and first clinical studies using SMAC mimetics in the treatment of solid tumour patients, such as breast and pancreatic cancer as well as lymphoma and leukaemia, are ongoing [52, 53]. Similarly, small molecules may block survivin through direct binding or more often by interacting with other cancer cell proteins [54, 55]. An alternative way of targeting survivin in cancer therapy is the use of survivin-based vaccines to generate a specific anti-survivin cytotoxic T-cell response. This type of immunotherapy has brought promising results in various cancers, including breast tumours $[55,56]$. Further investigations of the novel IAP specific treatment complimenting the standard chemotherapy would be a prospect for improvement of the long-term prognosis of LABC patients.

In conclusion, low/intermediate expression of XIAP and survivin in the pre-treatment biopsies in LABC patients treated with anthracycline-based chemotherapy was significantly associated with pCR and positively correlated with disease-free survival and overall survival. However, to better understand the role of IAP proteins in the response of tumours to treatment, further studies with study groups including larger numbers of $\mathrm{LABC}$ patients are required. They should also be based around a complete IAP family panel that considers subcellular diversion and other treatment regimens, such as chemotherapy, biological and hormone therapy.

\section{Acknowledgments}

We thank Mr Edward Lowczowski from the Medical University of Lodz for language assistance.

This work was supported by the sources of the Medical University of Lodz (Grant No. 503/1-03401/503-06-100).

\section{Conflict of interest}

The authors declare no conflict of interest.

\section{References}

1. Harding C, Pompei F, Burmistrov D, Wilson R. Long-term relationships between screening rates, breast cancer characteristics, and overdiagnosis in US counties, 19752009. J Cancer 2019; 144: 476-88.

2. Augustynowicz A, Czerw Al, Deptała A. Health needs as a priority of local authorities in Poland based on the example of implementation of health policy cancer programs. Arch Med Sci 2018; 14: 1439-49.

3. Woźniacki P, Skokowski J, Bartoszek K, Kosowska A, Kalinowski L, Jaśkiewicz J. The impact of the Polish mass breast cancer screening program on prognosis in the Pomeranian Province. Arch Med Sci 2017; 132: 441-7.

4. Simos D, Clemons M, Ginsburg OM, Jacobs C. Definition and consequences of locally advanced breast cancer. Curr Opin Support Palliat Care 2014; 8: 33-8.

5. Adams S, Chakravarthy AB, Donach M, et al. Preoperative concurrent paclitaxel-radiation in locally advanced breast cancer: pathologic response correlates with five-year overall survival. Breast Cancer Res Treat 2010; 124: 723-32.

6. Rastogi P, Anderson SJ, Bear HD, et al. Preoperative chemotherapy: updates of National Surgical Adjuvant Breast and Bowel Project Protocols B-18 and B-27. J Clin Oncol 2008; 26: 778-85.

7. Dawood S, Ueno NT, Valero V, et al. Differences in survival among women with stage III inflammatory and noninflammatory locally advanced breast cancer appear early: a large population-based study. Cancer 2011; 117: 1819-26.

8. Brito RA, Valero V, Buzdar AU, et al. Long-term results of combined-modality therapy for locally advanced breast cancer with ipsilateral supraclavicular metastases: the University of Texas M.D. Anderson Cancer Center experience. J Clin Oncol 2001; 19: 628-33.

9. Hanahan D, Weinberg Ra. The hallmarks of cancer. Cell 2000; 100: 57-70.

10. Dubrez-Daloz L, Dupoux A, Cartier J. IAPs: more than just inhibitors of apoptosis proteins. Cell Cycle 2008; 15: 1036-46.

11. Crook NE, Clem RJ, Miller LK An apoptosis-inhibiting baculovirus gene with a zinc finger-like motif. J Virol 1993; 67: 2168-74.

12. Liston P, Fong WG, Korneluk RG. The inhibitors of apoptosis: there is more to life than Bcl2. Oncogene 2003; 22: 8568-80.

13. Mohamed MS, Bishr MK, Almutairi FM, Ali AG. Inhibitors of apoptosis: clinical implications in cancer. Apoptosis 2017; 22: 1487-509.

14. Deveraux QL, Takahashi R, Salvesen GS, Reed JC. $X$-linked IAP is a direct inhibitor of cell-death proteases. Nature 1997; 388: 300-4.

15. Gao X, Zhang L, Wei Y, et al. Prognostic value of XIAP level in patients with various cancers: a systematic review and meta-analysis. J Cancer 2019; 10: 1528-37.

16. Pluta A, Wierzbowska A, Cebula-Obrzut B, et al. Prognostic value of inhibitor of apoptosis protein family expression in patients with acute myeloid leukemia. Leuk Lymphoma 2015; 56: 2529-35.

17. Yang XH, Feng ZE, Yan M, et al. XIAP is a predictor of cisplatin-based chemotherapy response and prognosis for patients with advanced head and neck cancer. PLoS One 2012; 7: e31601. 
18. Hussain AR, Siraj AK, Ahmed M, et al. XIAP over-expression is an independent poor prognostic marker in Middle Eastern breast cancer and can be targeted to induce efficient apoptosis. BMC Cancer 2017; 17: 640.

19. Pluta P, Jeziorski A, Cebula-Obrzut AP, et al. Expression of IAP family proteins and its clinical importance in breast cancer patients. Neoplasma 2015; 62: 666-73.

20. Xu YC, Liu Q, Dai JQ, et al. Tissue microarray analysis of X-linked inhibitor of apoptosis (XIAP) expression in breast cancer patients. Med Oncol 2014; 31: 764.

21. Parton M, Krajewski S, Smith I, et al. Coordinate expression of apoptosis-associated proteins in human breast cancer before and during chemotherapy. Clin Cancer Res 2002; 8: 2100-8.

22. Chen X, Duan N, Zhang C, Zhang W. Survivin and tumorigenesis: molecular mechanisms and therapeutic strategies. J Cancer 2016; 7: 314-23.

23. Ambrosini G, Adida C, Altieri DC. A novel anti-apoptosis gene, survivin, expressed in cancer and lymphoma. Nat Med 1997; 3: 917-21.

24. Wang W, Zhang B, Mani AM, et al. Survivin inhibitors mitigate chemotherapeutic resistance in breast cancer cells by suppressing genotoxic nuclear factor-kappaB activation. J Pharmacol Exp Ther 2018; 366: 184-93.

25. Li Y, Ma X, Wu X, Liu X, Liu L. Prognostic significance of survivin in breast cancer: meta-analysis. Breast J 2014; 20: 514-24.

26. Song J, Su H, Zhou YY, Guo LL. Prognostic value of survivin expression in breast cancer patients: a meta-analysis. Tumour Biol 2013; 34: 2053-62.

27. Kostadima L, Pentheroudakis G, Fountzilas G, et al. Survivin and glycodelin transcriptional activity in node-positive early breast cancer: mRNA expression of two key regulators of cell survival. Breast Cancer Res Treat 2006; 100: 161-7.

28. Span PN, Sweep FC, Wiegerinck ET, et al. Survivin is an independent prognostic marker for risk stratification of breast cancer patients. Clin Chem 2004; 50: 1986-93.

29. Sobin LH, Gospodarowicz MK, Wittekind C. TNM Classification of Malignant Tumours. $7^{\text {th }}$ ed. Wiley-Blackwell, 2009.

30. Allred DC, Harvey JM, Berardo M, Clark GM. Prognostic and predictive factors in breast cancer by immunohistochemical analysis. Mod Pathol 1998; 11: 155-68.

31. Pluta P, Jesionek-Kupnicka D, Kubicka-Wołkowska J, et al. SMAC protein expression as a potent favorable prognostic factor in locally advanced breast cancer. Pol J Pathol 2018; 69: 33-41.

32. Perrone F, Suardi S, Pastore E, et al. Molecular and cytogenetic subgroups of oropharyngeal squamous cell carcinoma. Clin Cancer Res 2006; 12: 6643-51.

33. Cohen J. Statistical power analysis for the behavioral sciences. $2^{\text {nd }}$ ed. Lawrence Erlbaum, New Jersey 1988.

34. Schemper M, Smith TL. A note on quantifying follow-up in studies of failure time. Control Clin Trials 1996; 17 343-6.

35. Hanley JA, McNeil BJ. The meaning and use of the area under a receiver operating characteristic (ROC) curve. Radiology 1982; 143: 29-36.

36. Evans MK, Sauer SJ, Nath S, Robinson TJ, Morse MA, Devi GR. X-linked inhibitor of apoptosis protein mediates tumor cell resistance to antibody-dependent cellular cytotoxicity. Cell Death Dis 2016; 7: e2073.

37. Aird KM, Ghanayem RB, Peplinski S, Lyerly HK, Devi GR. $\mathrm{X}$-linked inhibitor of apoptosis protein inhibits apoptosis in inflammatory breast cancer cells with acquired resistance to an ErbB1/2 tyrosine kinase inhibitor. Mo Cancer Ther 2010; 9: 1432-42.
38. Kennedy SM, O’Driscoll L, Purcell R, et al. Prognostic importance of survivin in breast cancer. Br J Cancer 2003; 88: 1077-83.

39. Zhao YC, Wang Y, Ni XJ, et al. Clinical significance of Smac and survivin expression in breast cancer patients treated with anthracycline-based neoadjuvant chemotherapy. Mol Med Rep 2014; 9: 614-20.

40. Lin Q, Liu Y, Chen H, et al. Survivin, Ki-67 and tumor grade as predictors of response to docetaxel-based neoadjuvant chemotherapy in locally advanced breast cancer. Mol Clin Oncol 2013; 1: 839-44.

41. Petrarca CR, Brunetto AT, Duval V, Brondani A, Carvalho GP, Garicochea B. Survivin as a predictive biomarker of complete pathologic response to neoadjuvant chemotherapy in patients with stage II and stage III breast cancer. Clin Breast Cancer 2011; 11: 129-34.

42. Boidot R, Vegran F, Lizard-Nacol S. Predictive value of survivin alternative transcript expression in locally advanced breast cancer patients treated with neoadjuvant chemotherapy. Int J Mol Med 2009; 23: 285-91.

43. Faversani A, Vaira V, Moro GP, et al. Survivin family proteins as novel molecular determinants of doxorubicin resistance in organotypic human breast tumors. Breast Cancer Res 2014; 16: R55.

44. Hamy AS, Bieche I, Lehmann-Che J, et al. BIRC5 (survivin): a pejorative prognostic marker in stage II/III breast cancer with no response to neoadjuvant chemotherapy. Breast Cancer Res Treat 2016; 159: 499-511.

45. Masood S. Neoadjuvant chemotherapy in breast cancers. Womens Health (Lond) 2016; 12: 480-91.

46. Cortazar P, Geyer CE Jr. Pathological complete response in neoadjuvant treatment of breast cancer. Ann Surg Oncol 2015; 22: 1441-6.

47. Untch M, Konecny GE, Paepke S, von Minckwitz G. Current and future role of neoadjuvant therapy for breast cancer. Breast 2014; 23: 526-37.

48. Kołacińska A, Chałubińska J, Błasińska-Morawiec M, et al. Pathological complete response in younger and older breast cancer patients. Arch Med Sci 2012; 8: 310-5.

49. https://www.nccn.org/professionals/physician_gls/pdf/ breast.pdf

50. Fortugno P, Wall NR, Giodini A, et al. Survivin exists in immunochemically distinct subcellular pools and is involved in spindle microtubule function. J Cell Sci 2002; 115: 575-85.

51. Collin LJ, Cronin-Fenton DP, Ahern TP, et al. Expression of survivin does not appear to influence breast cancer recurrence risk. Acta Oncol 2019; 58: 154-61.

52. Cossu F, Milani M, Mastrangelo E, Lecis D. Targeting the BIR domains of inhibitor of apoptosis (IAP) proteins in cancer treatment. Comput Struct Biotechnol J 2019; 25: 142-50.

53. Ali R, Singh S, Haq W. IAP proteins antagonist: an introduction and chemistry of Smac mimetics under clinical development. Curr Med Chem 2018; 25: 3768-95.

54. Xiao M, Xue Y, Wu Z, et al. Design, synthesis and biological evaluation of selective survivin inhibitors. J Biomed Res 2019; 22: 82-100.

55. Garg H, Suri P, Gupta JC, Talwar GP, Dubey S. Survivin: a unique target for tumor therapy. Cancer Cell Int 2016; 16: 49.

56. Onodi F, Maherzi-Mechalikh C, Mougel A, et al. High therapeutic efficacy of a new survivin LSP-cancer vaccine containing CD4+ and CD8+ T-Cell epitopes. Front Oncol 2018; 13: 517. 